\title{
MODELING A SECURE EXAM MANAGEMENT SYSTEM (SEMS) FOR MOBILE ENVIRONMENT BASED ON FACE RECOGNITION AND GPS TECHNIQUES
}

\author{
Hervé B. Olou ${ }^{1}$ and Eugène C. Ezin ${ }^{1,2}$ \\ ${ }^{1}$ Institut de Formation et de Recherche en Informatique, University of Abomey-Calavi, Republic of Benin \\ ${ }^{2}$ Institut de Mathématiques et de Sciences Physiques, University of Abomey-Calavi, Republic of Benin
}

\begin{abstract}
Learning anywhere at any time is the goal of Mobile learning (m-learning). With the proliferation of smartphones, some universities adopt m-learning to facilitate accessibility of documents and online courses for students. Teachers can plan for online assessment and students can join session, answer and see their score directly. During an exam, the challenge is to make sure that students don't cheat. In this paper, we propose a modeling of secure exam management system (SEMS) for m-learning. The system is composed of a mobile app and a server. The mobile app is specially developed for students and will be used during exams. When students start exam, random face recognition and location request will be run automatically to ensure that other students are not in the same place and that it is effectively the learner who is in front of his smartphone.
\end{abstract}

\section{KEYWORDS}

M-learning, Secure Exam System, E-exam, Face Recognition, Geolocation

\section{INTRODUCTION}

Mobile technology has an important impact in our life. It gives us a new manner to communicate, to access information, to work, to learn and many other facilities. Nowadays, mobile technology offers a new generation of learning tools for everybody, everywhere and at any time. Scholars believe that m-learning is an e-learning regardless location and time (Shukri N. and Razak A., 2011). According to Cavus N. and Uzunboylu H. (2009), m-learning introduces learning opportunities for geographically dispersed persons or students who are not able to go at school or university at a regular basis.

After a certain amount of courses, exams can be organized to validate the knowledge learnt. In m-learning system, the students are evaluated online. Omkar Urunkar et al. proposed a survey on designing a secure exam management system (SEMS) for m-learning environments (2016). They noted that SEMS have many disadvantages like slow services, security issues for exam and not being service oriented. About security issues, we have communication between students through internet, the exchange of mobile devices and the fact that students can be side by side during online exam.

The aim of this paper is to propose a model of system which allow students to take their exam everywhere without cheating. To reach this goal, we have based the system on two main techniques: face recognition and global positioning system (GPS). The contribution of this paper is essentially the integration of these techniques in SEMS for m-learning environments.

This paper is organised into four sections. The first section presents the use of face recognition in the system. In the second section, we talk about the use of geolocation. In the third section, we present the global architecture of the system. The last section resumes our work and presents perspectives for future works. 


\section{FACE RECOGNITION}

Several mobile phones have front-facing camera. This front-facing camera can be used to implement a SEMS for m-learning environments with face recognition. Face recognition is an appropriate mechanism for anti-usurpation. It is a usable, highly secure, and efficient biometric-based authentication mechanism that can be adopted as a second authentication factor (Mustafa K. et al, 2016). Students will be registered on the system with their pictures. Thus, the system can recognize them by using front-facing camera.

During an exam on mobile phone, students can easily cheat by:

- exchanging mobile phone with other students;

- $\quad$ giving their mobile phone to another person who will take exam for them;

- making research on internet or writing to another student to get answer of the questions; etc.

By face recognition, we can limit this cheating. If the system detects that it's not the student who is identified at the front of the mobile device, the session of this student will be automatically terminated. The different steps of the face recognition mechanism in our system are:

- $\quad$ the first step is the student registration. All students must be enrolled in the system with information about email, login, password and pictures;

- the second step is the starting exam session. With the mobile app, the student will be connected thanks to his login and password. Thereafter, he will start the exam session accessing to questions;

- the last step is the face recognition by the mobile app. During exam, face recognition will be done in the background. It will be done automatically at random times. After three failure attempts of face recognition, the session of the student will be automatically terminated.

Face recognition can be affected by the quality of the front-facing camera and the luminosity. Before the online assessment, students will be informed about these and they can make all necessary arrangements for a good face recognition.

Furthermore, the establishment of a powerful facial recognition system must take into account certain parameters like eyes blinking. Indeed, someone can use picture of a student and take exam for another student. So, by detecting eyes blinking in a video sequence, we can ensure the exact identity of the student in the front of the mobile device.

\section{USAGE OF GEOLOCATION}

During a face-to-face exam, a minimum distance must be set between students to avoid them exchanging information. This rule must also be respected during online exam. Several mobile phones have a Global Positioning System (GPS). Generally, GPS is used for tracking an object, animal or people. In our case, it will be used to track the student's mobile devices during the exam.

By using GPS functionality of mobile devices, the server will get the GPS coordinates of the student mobile phone. Then, it will check if different students have the same coordinates at the same time or the minimum required distance between students is respected. If these conditions are not respected, the server will send a request to the mobile app to close and send the answers of the students. After that, the session of these students are closed and their answers sent to the server for getting marks.

On the system, we use geolocation like this:

- $\quad$ at the beginning and during the exam, the mobile app communicates the GPS coordinates of the mobile devices to the server;

- the server makes the comparison of the GPS coordinates of students mobiles devices. If some wrong thing is detected, the student session will be close;

- $\quad$ on mobile app, students can see the positions of the examination centers and they can choose one of them.

\section{GLOBAL ARCHITECTURE}

This section shares the global architecture of the system. This architecture is presented in Figure 1. All students are previously enrolled in the system. Before starting exam session, the student chooses the exam. 
A teacher can decided to make an exam with a supervisor. On the system, different places like library, primary school, private school or university will be enrolled with their supervisors. Thus, students who are far from the university can decided to take exam on one of the registered centers by using the map frame on the mobile app of the SEMS.

If the exam can be made without a supervisor, the student will start the session. Else, he will see the list of examination centers and chooses one. The supervisor of this center will validate, if the student is there. Thereafter, the student can start exam session. In spite of the supervisor's presence, the system will continue to use the geolocation and face recognition.
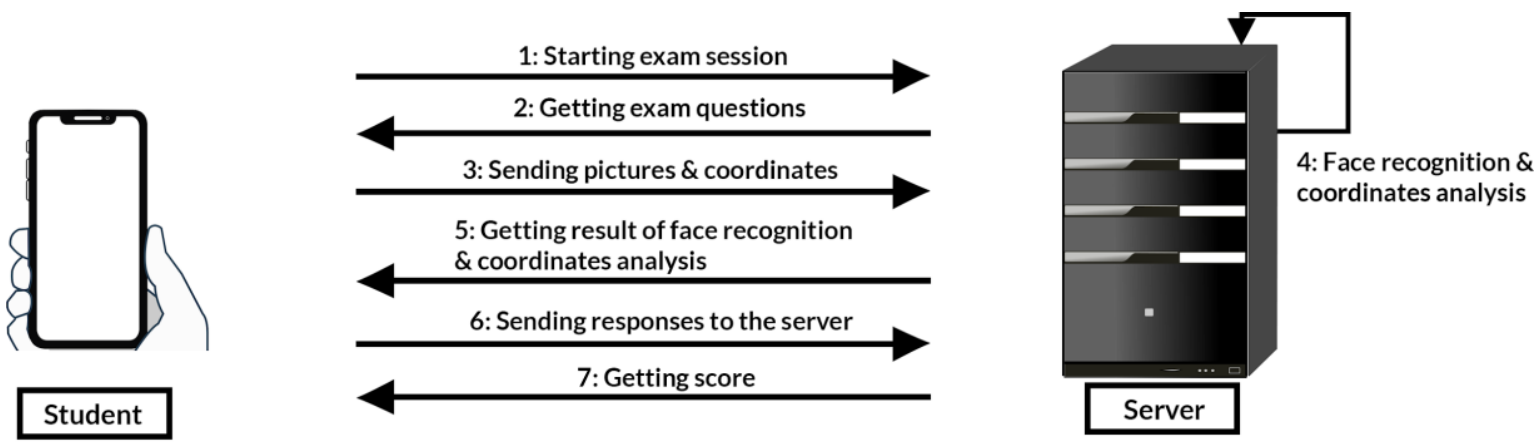

Figure 1. Global architecture

The global architecture has seven steps:

- At the first step, the student starts the exam session after logging into the system and choosing the exam. The mobile app sends a request to the server to get the exam questions.

- Then, at the second step, the server sends the exam questions to the mobile app according to the description of the exam (course, type of exam, duration, etc.).

- Pictures and GPS coordinates of the student are sent to the server at the third step. As soon as the student begins the exam, the mobile app sends automatically these data to the server to prevent cheating during the exam.

- At the fourth step, the data sent previously are analyzed by the server. It's the heart of the system. The main work is done at this step, as described in sections 2 and 3.

- Now, at the fifth step, if some wrong thing is detected, the server will request the closure of the student's session. Else, the session will remain active.

- The assessment of the questions are sent at the sixth step. At this step, the student finished his exam or the server detects some wrong thing at the fifth step. So, his answers are sent to the server.

- Finally, at the last step, the student gets his score. His session will be closed and all restrictions will be canceled.

The mobile app must be able to:

- block incoming calls. During the exam, a call can disturb the student;

- verify if the application is foreground or background. This check is important to detect if the student is using another application (browser, excel, Whatsapp, Facebook message, etc.) during the exam. If he uses another application, his session will be closed and his answer will be sent to the server.

- take pictures, send pictures and GPS coordinates without affecting the student exam. These data will be analysed by the system during the exam.

\section{CONCLUDING REMARKS}

In this paper, we present the modeling that combines face recognition and GPS technique for SEMS. The aim of this work is to guarantee an effective exam without cheating. By using face recognition, students are constrained to put their phone in front of their face. Thus, during an exam they can't exchange their mobile device with another student. Moreover, no one can take exam for another. The use of geolocation in this 
system comes to ensure that students are not side by side during the exam. If an exam requires a supervisor, the students will see the closest center to him on the mobile app.

Our system is under development. In future work, we plan to implement the prototype and integrate it into an existing learning management system (LMS). A low energy battery cannot provide power supply for longer period. Hence, improving the energy efficiency in mobile learning framework is also crucial (Asir, D. et al., 2017). The efficiency of this system must be studied too.

\section{REFERENCES}

Asir, D. et al., 2017. Mobile Application for m-Learning. In International Journal of Advanced Research in Computer Science, Vol. 8, No. 3, pp. 313-316.

Cavus, N. and Uzunboylu, H., 2009. Improving critical thinking skills in mobile learning. In World Conference on Educational Sciences 2009, pp. 434-438.

El-Hussein, M. et al., 2010. Defining mobile learning in the higher education landscape. In Educational Technology \& Society, Vol. 13, No. 3, pp. 12-21.

Kaiiali, M. et al., 2016. Designing a Secure Exam Management System (SEMS) for M-Learning Environments. In IEEE Transactions on learning technologies, Vol. 9, No. 3, pp. 258-271.

Moldovan, A. et al., 2014. Energy Aware Mobile Learning: Opportunities and Challenges. In IEEE Communications Surveys \& Tutorials, Vol. 16, No. 1, pp. 234-265.

Shukri, N. and Razak, A., 2011. Students' Awareness and Requirements of Mobile Learning Services in the Higher Education Environment. In American Journal of Economics and Business Administration 3 (1), pp. 95-100. 